\title{
Hybrid $\mathrm{TiO}_{2} / \mathrm{WO}_{3}$ nanoparticles fabricated via a sol-gel process using amphiphlic poly(e-caprolactone)-block-poly(acrylic acid) diblock copolymer as template and their high visible light photocatalytic activity
}

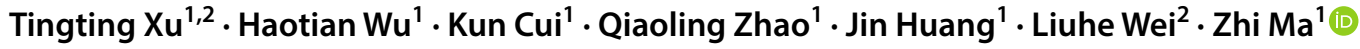

(c) Springer Nature Switzerland AG 2019

\begin{abstract}
The hybrid $\mathrm{TiO}_{2} / \mathrm{WO}_{3}$ nanoparticles with different doping ratios of tungsten were synthesized from titanium tetra-isopropoxide and tungsten hexachloride $\left(\mathrm{WCl}_{6}\right)$ as precursors via a sol-gel process using poly( $\varepsilon$-caprolactone)- $b$-poly(acrylic acid) (PCL-b-PAA) diblock copolymer as a template. The morphology, crystal structure, chemical and physical property of the fabricated $\mathrm{TiO}_{2} / \mathrm{WO}_{3}$ nanoparticles were characterized by scanning electron microscopy, transmission electron microscopy, powder X-ray diffraction, $\mathrm{X}$-ray photoelectron spectroscopy and so on. $\mathrm{N}_{2}$ adsorption-desorption analysis revealed that the surface area $\left(40.6 \mathrm{~m}^{2} \mathrm{~g}^{-1}\right)$, pore volume $\left(0.11 \mathrm{~cm}^{3} \mathrm{~g}^{-1}\right)$ and average pore size $(8.56 \mathrm{~nm})$ of such $\mathrm{TiO}_{2} / \mathrm{WO}_{3}$ nanoparticles. The resulting hybrid $\mathrm{TiO}_{2} / \mathrm{WO}_{3}$ nanoparticles (average diameter: ca. 100-200 nm) with proper doping ratio of tungsten exhibited the enhanced photocatalytic activity than that of the commercial P25 in the degradation of methylene blue.
\end{abstract}

\section{Graphic Abstract}

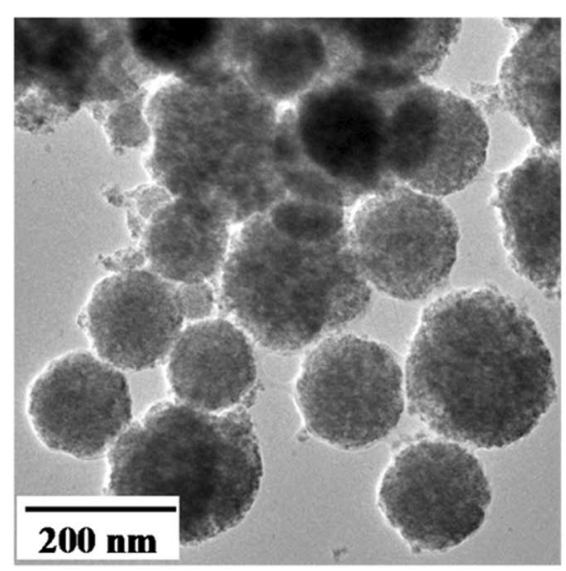

TEM image of hybrid $\mathrm{TiO}_{2} / \mathrm{WO}_{3}$ precursor nanoparticles ( $\mathrm{Ti}: \mathrm{W}=85: 15$ ) after acetone extraction several times.

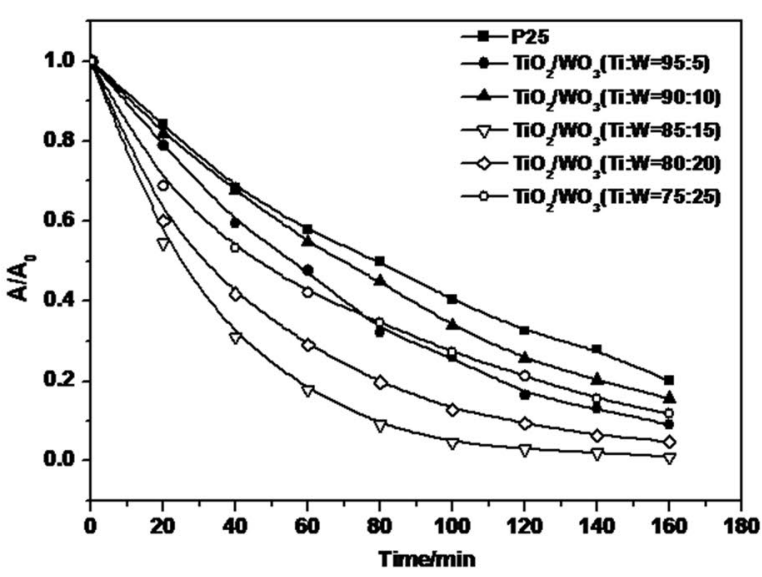

Photodegradation curves of methylene blue catalyzed by hybrid $\mathrm{TiO}_{2} / \mathrm{WO}_{3}$ nanoparticles with different Ti/Wratios and $\mathrm{P} 25$.

Keywords $\mathrm{Hybrid} \mathrm{TiO}_{2} / \mathrm{WO}_{3}$ nanoparticles · Sol-gel process · Template · Block copolymer · Photocatalysis

$\square$ Liuhe Wei, weiliuhe@zzu.edu.cn; $\square$ Zhi Ma, mazhi728@sioc.ac.cn | ${ }^{1}$ Key Laboratory of Synthetic and Self-Assembly Chemistry for Organic Functional Molecules, Center for Excellence in Molecular Synthesis, Shanghai Institute of Organic Chemistry, Chinese Academy of Sciences, 345 Lingling Road, Shanghai 200032, People's Republic of China. ${ }^{2}$ Zhengzhou Key Laboratory of Elastic Sealing Materials, College of Chemistry and Molecular Engineering, Zhengzhou University, Zhengzhou 450002, People's Republic of China. 


\section{Introduction}

Amphiphilic diblock copolymer is formed by the junction of covalent bond between one hydrophilic polymer segment and the other hydrophobic polymer segment, which can form micelles or aggregates by self-assembly in selective solvent because of the thermodynamic incompatibility between two different polymer segments and phase separation characteristics. Therefore, it can form micronor nano-scale micro-reactor in solution with controllable size by regulating the length and property of polymer segments [1]. Meanwhile, different shapes of micro-reactor such as ball, rod and vermicular, etc. can be obtained by changing the solvent composition, $\mathrm{pH}$, temperature during the amphiphilic diblock copolymer's self-assembly [2, 3].

Poly( $\varepsilon$-caprolactone) (PCL) is a kind of semicrystalline polymer with good biocompatibility, biodegradability and etc. [4]. In recent years, the polymer self-assembly technology has received considerable attention, and the amphiphilic diblock copolymer prepared from hydrophobic polycaprolactone and hydrophilic polymer is the focus of attention. Poly(acrylic acid) (PAA) is a pH sensitive weak electrolyte, it can unite with nonionic polymers electron acceptor and cationic polyelectrolyte, and interact with cations [5]. Therefore, the synthesis of amphiphilic copolymer contains PCL and PAA blocks make great significance, since it can not only improve the such polymer's performance, but also expand the its application [6].

With the continuous development of nanotechnology, multifunctional nanocomposite draws more and more attention, especially that based on block copolymer templates [7]. The preparation of nanometer materials was optimized because of the block copolymers' properties. Several synthetic methodologies have been widely developed to prepare $\mathrm{TiO}_{2}$ material with significant properties, such as sol-gel method [8-11], micelle and inverse micelle methods [12-14], sol method [15, 16], hydrothermal method [17-21], evaporation-induced selfassembly method [21], solvo-thermal method [22, 23], chemical vapor deposition [24], physical vapor deposition [25], direct oxidation method [26], and so on. The sol-gel process is one of the most widely used methodology for preparing nanoparticles due to several advantages, such as high purity, good uniformity, low processing temperature, stability and versatility of processing $[27,28]$. And the sol-gel process with diblock copolymer as template has been applied in the preparation of thin film, ceramic fiber materials, microporous inorganic membrane, porous aerogel material and functional composite $[29,30]$. Nanometer $\mathrm{TiO}_{2}$ has became one of research hotspots in the field of material due to its significant physical and chemical properties. It has good stability, high catalytic efficiency, no secondary pollution, non-toxic and low cost as photocatalyst, and has special advantages in the degradation of toxic and refractory organic matter and inorganic matter. $\mathrm{TiO}_{2}$ photocatalysis material has practical application in many areas, such as the self-cleaning materials, air purification, wastewater treatment, super hydrophilic coating, etc. [31].

While, with the exponential growth of research activities, modified doping have been widely progressed, such as nonmetallic doping [32-38], metallic doping [39-42] and semiconductor doping [43-47]. Among the variety of methods targeting improve the photocatalytic activities, the semiconductor doping attracted much attention. Since the semiconductor of different width forbidden band compounded with each other, urging the separation of electronic-hole, reducing electronic restructuring, widen the range of spectral response, further improve the photocatalytic efficiency in consequence. Carcel et al. [43] reported the photodegradation for methyl orange $(\mathrm{MO})$ of $\mathrm{TiO}_{2}, \mathrm{WO}_{3}$ and $\mathrm{TiO}_{2} / \mathrm{WO}_{3}$ films in different $\mathrm{pH}$, and get films of improved photocatalytic efficiency with the addition of $\mathrm{H}_{2} \mathrm{O}_{2}$. Yang et al. [44] obtained composite that shows higher acetaldehyde degradation efficiency than mono$\mathrm{TiO}_{2}$ in the presence of $\mathrm{WO}_{3}$, and studied the effect on the different ratio of $\mathrm{W} / \mathrm{Ti}$ compounds on the degradation efficiency. Ren et al. [45] reported $\mathrm{TiO}_{2}-\mathrm{SiO}_{2}$ catalyst that prepared using $\mathrm{TiOSO}_{4} \cdot 2 \mathrm{H}_{2} \mathrm{O}$ and $\mathrm{SiO}_{2}$ as precursor, and show fine catalysis activity after calcinations. Fateh et al. [46] obtained $\mathrm{TiO}_{2}-\mathrm{SiO}_{2}$ films via dip-coating method on polycarbonate resin template showing improved photocatalytic efficiency after the combination of $\mathrm{SiO}_{2}$.

Herein, we report the synthesis of hybrid $\mathrm{TiO}_{2} / \mathrm{WO}_{3}$ nanoparticles via a sol-gel process by self-assembly amphiphilic diblock copolymer PCL-b-PAA as the template, toluene as solvent, using titanium tetra-isopropoxide (TTIP) and tungsten hexachloride $\left(\mathrm{WCl}_{6}\right)$ as precursor. Transmission electron microscopy (TEM), scanning electron microscope (SEM), X-ray diffraction analyzer (XRD), X-ray photoelectron spectroscopy analyzer (XPS), UV-Visible spectroscopy (UV-vis), thermal gravity analysis (TGA), etc. had been used to characterize the morphology, structure and performance of hybrid $\mathrm{TiO}_{2} / \mathrm{WO}_{3}$ nanoparticles. The effects of different doping ratios on photocatalytic performance of $\mathrm{TiO}_{2} / \mathrm{WO}_{3}$ nanoparticles were investigated in terms of degradation of methylene blue (MB). 


\section{Experimental}

\subsection{Chemicals and materials}

The amphiphilic diblock copolymer, poly( $\varepsilon$-caprolactone)block-poly(acrylic acid) (PCL-b-PAA) $\left[M_{\mathrm{w}} / M_{\mathrm{n}}=1.18 ; M_{\mathrm{n}}\right.$ $(\mathrm{PCL})=8600 \mathrm{~g} \mathrm{~mol}^{-1} ; M_{\mathrm{n}}(\mathrm{PAA})=4200 \mathrm{~g} \mathrm{~mol}^{-1}$ ] prepared in a similar procedure reported in our previous work [6], acted as a template in sol-gel process. Toluene was refluxed over sodium and distilled under a nitrogen atmosphere before use. Concentrated hydrochloric acid $(\mathrm{HCl}, 37 \%)$ and methylene blue $(\mathrm{MB})$ were purchased from Sinopharm Chemical Reagent Co. Ltd. Titanium tetra-isopropoxide (TTIP) and tungsten hexachloride $\left(\mathrm{WCl}_{6}\right)$ were purchased from Aladdin Chemistry Co. Ltd.

\subsection{Preparation of hybrid $\mathrm{TiO}_{2} / \mathrm{WO}_{3}$ nanospheres}

All manipulations involving low moisture conditions were carried out using Schlenk techniques. In a typical preparation, $200 \mathrm{mg}$ dried PCL- $b$-PAA was dissolved in $12 \mathrm{~mL}$ toluene under nitrogen atmosphere in a Schlenk tube with a magnetic stir bar. Then, $1 \mathrm{~mL} \mathrm{WCl}{ }_{6}$ solution in toluene $\left(0.1 \mathrm{~g} \mathrm{~mL}^{-1}\right)$ was injected into the reaction system. The solution was stirred for $1 \mathrm{~h}$ at room temperature. After that $0.4 \mathrm{~mL}$ TTIP was added to the solution and stirred for $2 \mathrm{~h}$. Then, $0.1 \mathrm{~mL} \mathrm{HCl}(37 \%)$ was added into the solution. The mixture was stirred for $2 \mathrm{~h}$ and aged for $24 \mathrm{~h}$ at room temperature. The different molar ratio of TTIP and $\mathrm{WCl}_{6}$ in Ti:W=95:5, 90:10, 85:15, 80:20 and 75:25 were employed respectively. After that the sample was annealed at $100^{\circ} \mathrm{C}$ for $1 \mathrm{~h}$ followed by calcination at $500^{\circ} \mathrm{C}, 600^{\circ} \mathrm{C}$ or $700^{\circ} \mathrm{C}$ for $5 \mathrm{~h}$.

To obtain the $\mathrm{TiO}_{2} / \mathrm{WO}_{3}$ precursor nanoparticles for TEM observation, the mixed precursor solution in the Schlenk tube was extracted by acetone several times to remove the polymer residue. The mixture was then added into $30 \mathrm{~mL}$ acetone and stirred for $30 \mathrm{~min}$. After centrifuging the solution, the supernatant was removed by a dropper. This process was repeated 5 times. A suspension of $\mathrm{TiO}_{2} /$ $\mathrm{WO}_{3}$ precursor nanoparticles was obtained and observed by TEM.

\subsection{Instruments and measurements}

The as-synthesized $\mathrm{TiO}_{2} / \mathrm{WO}_{3}$ nanoparticles before and after calcinations were characterized by SEM (JSM-6390LV, JEOL Ltd.), TEM (JEM-1400, 120 kV, JEOL Ltd.), powder $X$-ray diffraction (XRD) (Cu-Ka radiation $(\lambda=1.5418 \AA$ ), $X$ 'pert PRO, Panalytical Co.) and X-ray photoelectron spectroscopy (XPS) (Al-Ka radiation ( $\mathrm{hv}=1486.6 \mathrm{eV}$ ), Thermo
ESCALAB 250Xi, USA). The UV-Visible absorption spectra were recorded with a UNICO UV-2102PC spectrophotometer. Nitrogen adsorption-desorption isotherms of $\mathrm{TiO}_{2} /$ $\mathrm{WO}_{3}$ nanoparticles were measured by Micromeritics ASAP 2020 surface area and porosity analyser. The photocurrent measurements of $\mathrm{TiO}_{2} / \mathrm{WO}_{3}$ spin-coated film were carried out with a CHI $660 \mathrm{C}$ workstation. The photoluminescence $(\mathrm{PL})$ analyses were measured at room temperature by a Fluorolog-3-P UV-VIS-NIR fluorescence spectrophotometer illuminated with a $360 \mathrm{~nm} \mathrm{He-Cd}$ laser.

\subsection{Photocatalytic activities}

The photocatalytic activity of the hybrid $\mathrm{TiO}_{2} / \mathrm{WO}_{3}$ nanoparticles was tested under visible light. A $400 \mathrm{~W}$ highpressure mercury lamp was placed $10 \mathrm{~cm}$ away from the reaction vessel, which was used to provide a full-spectrum emission without any filter to simulate the sunlight source. The illumination intensity was $5 \mathrm{~W} \mathrm{~m}^{-2}$. The photocatalytic activities of $\mathrm{TiO}_{2} / \mathrm{WO}_{3}$ nanoparticles were evaluated by photodegradation of $\mathrm{MB}$. The selected photocatalyst was dispersed in the $\mathrm{MB}$ solution $\left(10 \mathrm{mg} \mathrm{mL}^{-1}\right)$ to achieve a concentration of $1 \mathrm{mg} \mathrm{mL}^{-1}$. The mixed suspension was first stirred in the dark for $1 \mathrm{~h}$ to reach the adsorption-desorption equilibrium of $\mathrm{MB}$. The concentration of residual $M B$ was determined by recording the decrease in the maximum absorbance of $M B$ at $654 \mathrm{~nm}$ after various reaction times using UV-vis spectrophotometer every $20 \mathrm{~min}$.

\section{Results and discussion}

$\mathrm{TiO}_{2} / \mathrm{WO}_{3}$ precursor nanoparticles were formed inside the PCL- $b$-PAA micelles with PCL segment as "shell" and the PAA segment as "core" [45] which coordinated with $\mathrm{WCl}_{6}$ and TTIP. Although extracted by acetone several times, $\mathrm{TiO}_{2} / \mathrm{WO}_{3}$ precursors particles with irregular morphology were still formed (Fig. 1a). However, spherical nanoparticles of $\mathrm{TiO}_{2} / \mathrm{WO}_{3}$ could be formed (Fig. 1b) after acetone extraction followed by calcinations at $600^{\circ} \mathrm{C}$ for $5 \mathrm{~h}$.

TEM observation (Fig. 2) showed that $\mathrm{TiO}_{2} / \mathrm{WO}_{3}$ precursor after acetone extraction several times appeared as regular spheres with diameter size from 100 to $200 \mathrm{~nm}$. Such spherical morphology indicated that the hydrolysis of TTIP and $\mathrm{WCl}_{6}$ happened in the core of the PCL-b-PAA micelles as templating agent. The effects of the molar ratio of $\mathrm{PCL} / \mathrm{PAA}$ segment, the molar ratio of TTIP/ $/ \mathrm{WCl}_{6} / \mathrm{PAA}$ and etc. on the morphology and property of the obtained $\mathrm{TiO}_{2} /$ $\mathrm{WO}_{3}$ nanoparticles are under investigation.

Energy dispersive spectroscopy (EDS) analysis was conducted to confirm the composition of the hybrid $\mathrm{TiO}_{2} / \mathrm{WO}_{3}$ nanoparticles as shown in Fig. 3. The characteristic peaks of $\mathrm{Ti}, \mathrm{W}, \mathrm{O}$ and $\mathrm{C}$ atoms can be clearly 
Fig. 1 SEM images of hybrid $\mathrm{TiO}_{2} / \mathrm{WO}_{3}$ nanoparticles (Ti:W=85:15): $\mathbf{a}$ after acetone extraction without calcination; b after acetone extraction and calcination at $600{ }^{\circ} \mathrm{C}$ for $5 \mathrm{~h}$

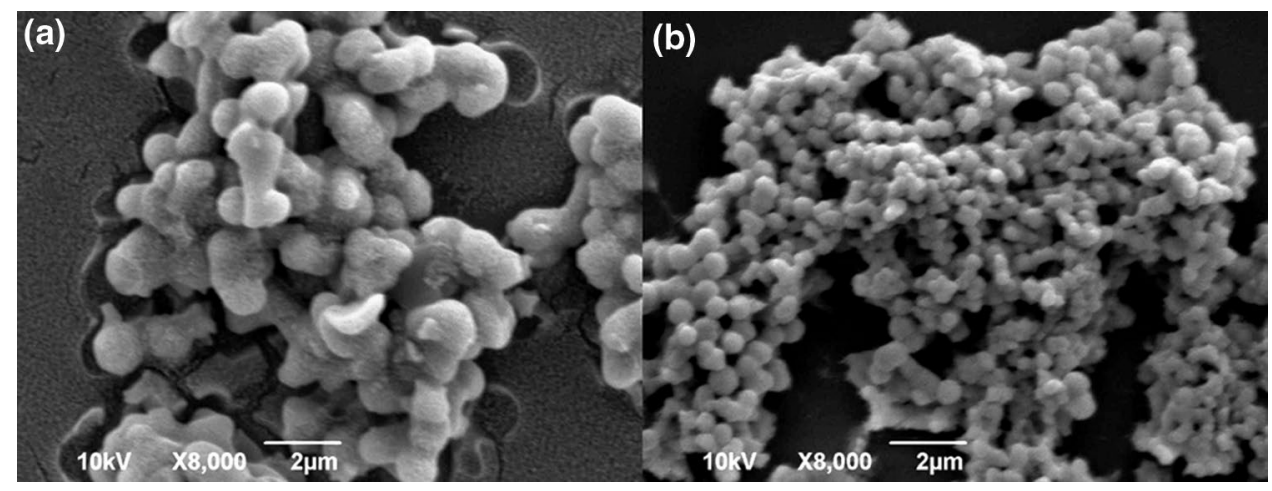

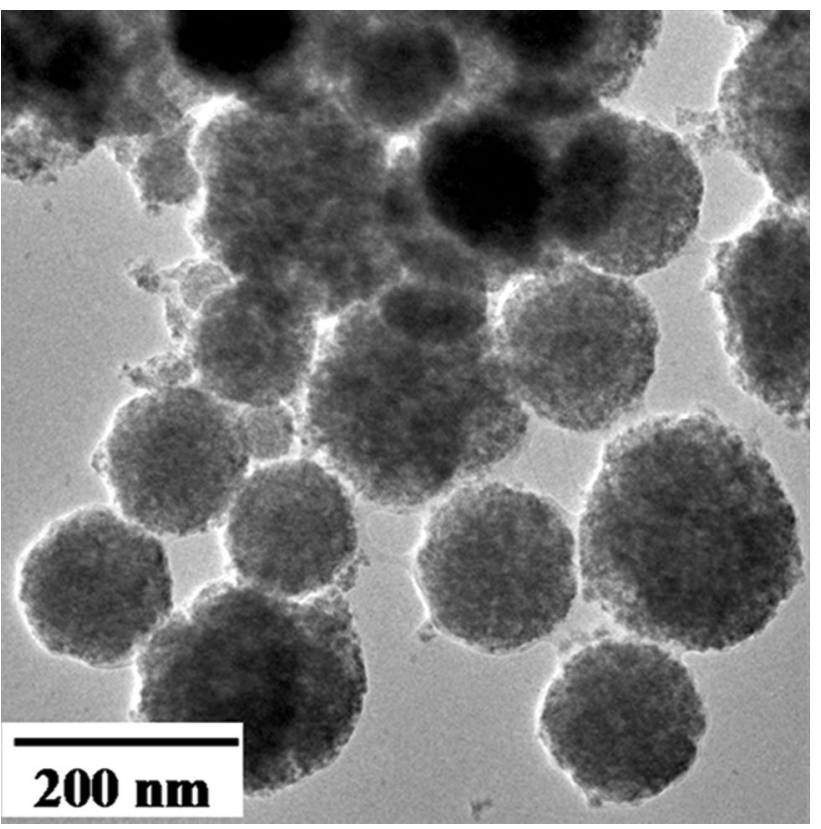

Fig. 2 TEM image of hybrid $\mathrm{TiO}_{2} / \mathrm{WO}_{3}$ precursor nanoparticles (Ti:W=85:15) after acetone extraction several times

identified. The presence of $C$ atom is probably attributed to residual $C$ atom produced from the incomplete removal of PCL- $b$-PAA even after calcinations [48-50].

Figure 4 shows the typical XRD patterns of the $\mathrm{TiO}_{2} /$ $\mathrm{WO}_{3}$ nanoparticles calcinated at various temperatures for $5 \mathrm{~h}$. At $500{ }^{\circ} \mathrm{C}$, the anatase peaks were mainly observed in the XRD patterns. At $700^{\circ} \mathrm{C}$, the rutile crystal peaks can be clearly identified, which reveals the temperature has a great impact on the transformation of crystal structure [51]. Also the peaks of orthorhombic $\mathrm{WO}_{3}$ were observed at $700^{\circ} \mathrm{C}$, compared with the weak peaks at $500^{\circ} \mathrm{C}$ and $600^{\circ} \mathrm{C}$, which may caused by the formation of amorphous $\mathrm{WO}_{3}$. The anatase-to-rutile transformation temperature has been mostly reported from 600 to $900^{\circ} \mathrm{C}$ for the initiation and finishing temperature, respectively [52].

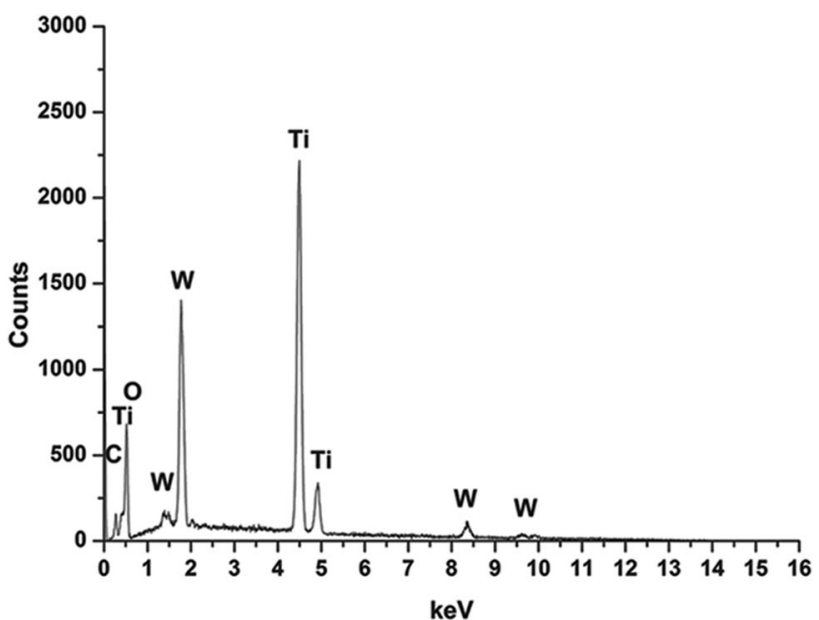

Fig. 3 EDS spectrum of hybrid $\mathrm{TiO}_{2} / \mathrm{WO}_{3}$ nanoparticles (Ti:W=85:15) after calcination at $600^{\circ} \mathrm{C}$ for $5 \mathrm{~h}$

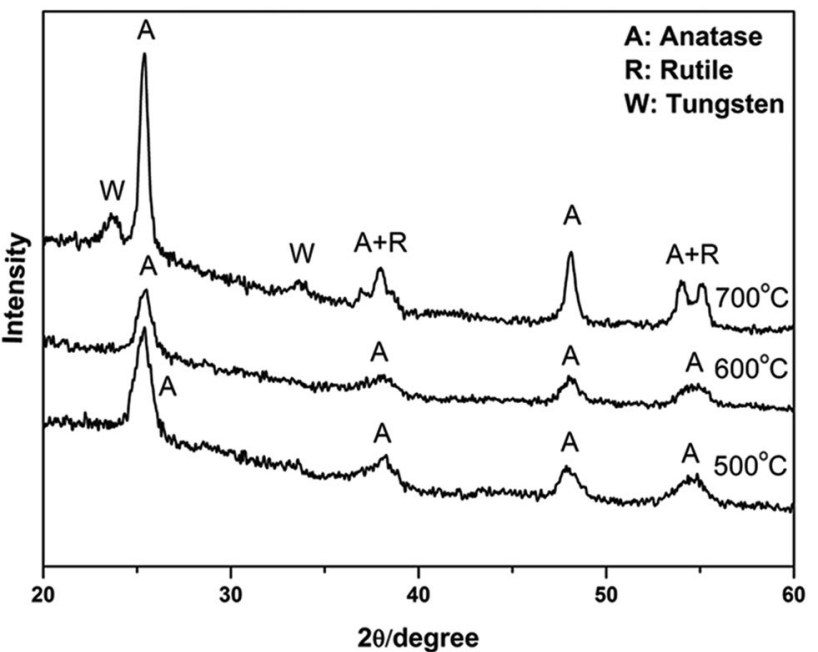

Fig. 4 The XRD patterns of hybrid $\mathrm{TiO}_{2} / \mathrm{WO}_{3}$ nanoparticles calcinated at $500{ }^{\circ} \mathrm{C}, 600{ }^{\circ} \mathrm{C}$ and $700{ }^{\circ} \mathrm{C}$, respectively. A denotes anatase phase of $\mathrm{TiO}_{2}, \mathrm{R}$ denotes rutile phase of $\mathrm{TiO}_{2}$ and $\mathrm{W}$ denotes orthorhombic $\mathrm{WO}_{3}$, respectively

\section{SN Applied Sciences}



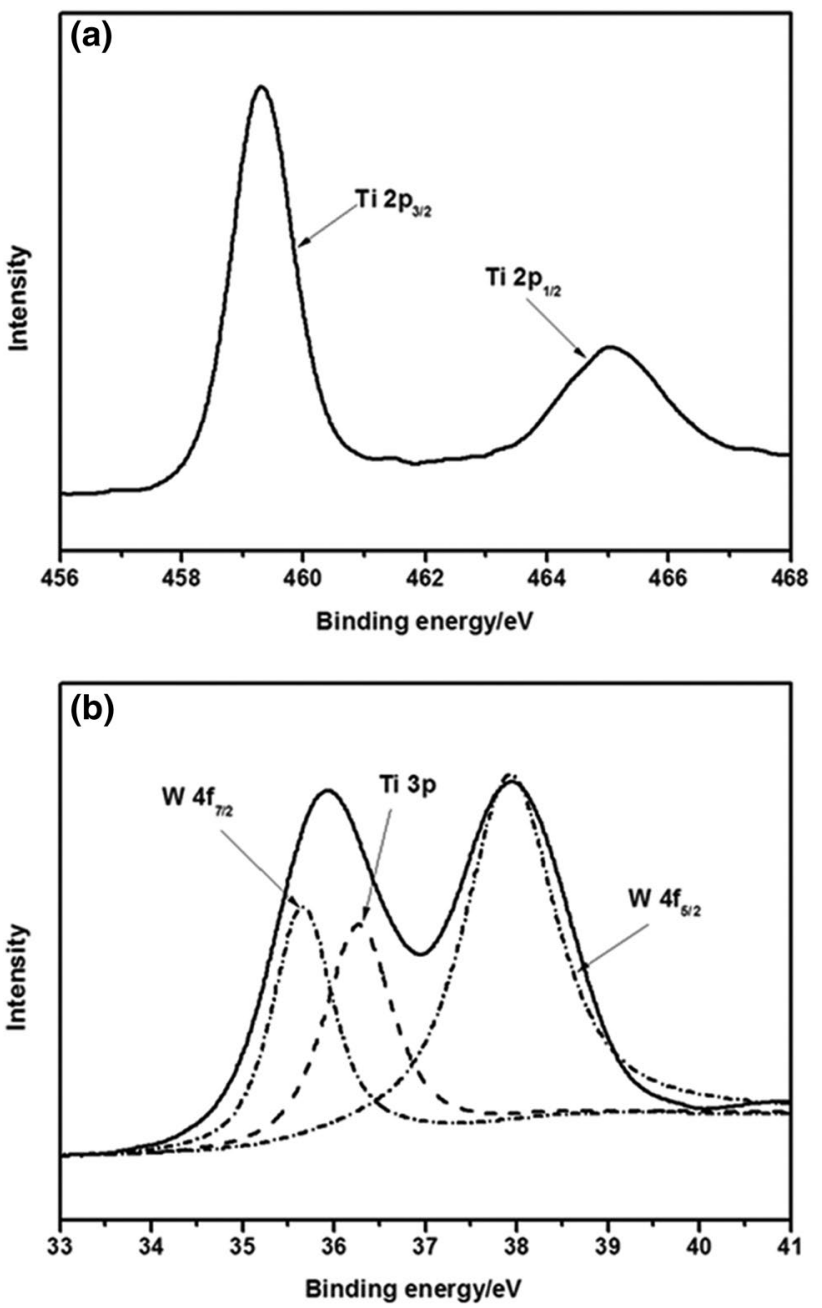

Fig. 5 XPS spectra of $\mathbf{a}$ Ti2p and $\mathbf{b}$ W4f and Ti3p of hybrid $\mathrm{TiO}_{2} / \mathrm{WO}_{3}$ nanoparticles (Ti:W=85:15) after calcination at $600{ }^{\circ} \mathrm{C}$. The solid lines are experimental spectra and the others are fitting ones

XPS spectra of $\mathrm{TiO}_{2} / \mathrm{WO}_{3}$ nanoparticles displays two peaks at $459.1 \mathrm{eV}$ and $464.8 \mathrm{eV}$ (Fig. 5a) resulted by the spin orbit split of Ti2p, indicating the existence of the Ti-O bonds. Furthermore, the measured binding energy value is higher than the standard one is attribute to the transformation of Ti-O-Ti to Ti-O-W. Figure $5 \mathrm{~b}$ showed the result of fitting peak separation curve. The peaks at $35.5 \mathrm{eV}$ and $37.8 \mathrm{eV}$ are attributed to the formation of $\mathrm{W}^{6+}$, existing in the form of $\mathrm{WO}_{3}$. While, the peak at $36.3 \mathrm{eV}$ is corresponded to the Ti3p.

Figure 6 shows the cyclic voltammetry curve of $\mathrm{TiO}_{2} /$ $\mathrm{WO}_{3}$ (Ti:W=85:15) spin-coated film after calcinations at $600{ }^{\circ} \mathrm{C}$. The closed circular curve demonstrates the coloring-fading process is reversible. There are two obvious anodic peak, corresponding to the different active points formed when $\mathrm{Li}^{+}$and $\mathrm{H}^{+}$are injected to the $\mathrm{TiO}_{2} / \mathrm{WO}_{3}$ film.

Photoluminescence emission spectra (PL) have been widely used to investigate the efficiency of charge

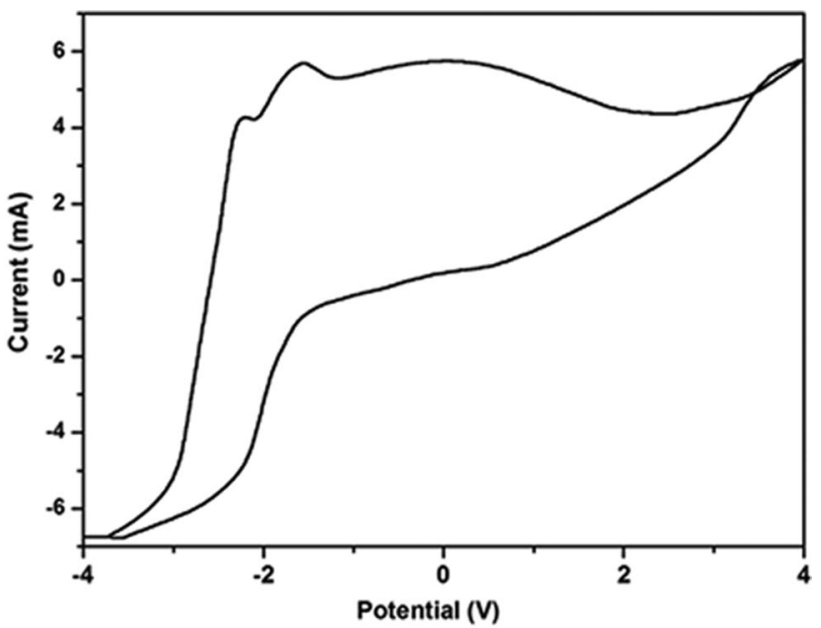

Fig. 6 Cyclic voltammetry curve of $\mathrm{TiO}_{2} / \mathrm{WO}_{3}(\mathrm{Ti}: \mathrm{W}=85: 15)$ spincoated film after calcination at $600^{\circ} \mathrm{C}$

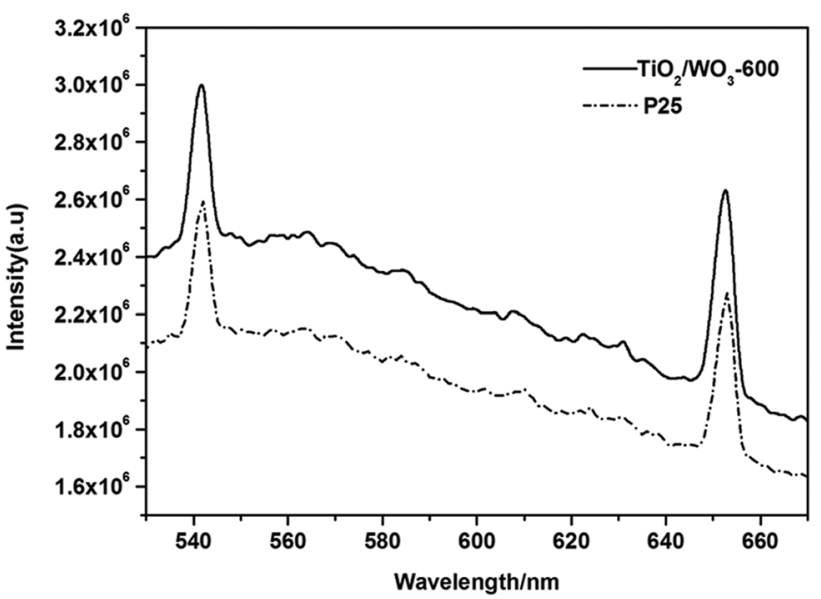

Fig. $7 \mathrm{PL}$ spectra of $\mathrm{TiO}_{2} / \mathrm{WO}_{3}-600$ nanoparticles (Ti:W $=85: 15$, calcinated at $600^{\circ} \mathrm{C}$ ) and $\mathrm{P} 25$

trapping, immigration, transfer and to understand the fate of electron-hole pairs about the semiconductor particles [53]. Figure 7 shows the $\mathrm{PL}$ spectra of $\mathrm{TiO}_{2} / \mathrm{WO}_{3}-600$ ( $\mathrm{Ti}: \mathrm{W}=85: 15$, calcinated at $600^{\circ} \mathrm{C}$ ) and $\mathrm{P} 25$. It can be seen that the PL intensity of $\mathrm{TiO}_{2} / \mathrm{WO}_{3}$ is much lower than that of $\mathrm{P} 25$. This indicated that $\mathrm{WO}_{3}$ doping can effectively inhibit the recombination of photo-generated electrons and holes, in consequence the separation of light carriers inside $\mathrm{TiO}_{2} / \mathrm{WO}_{3}$ film is much better, and the absorption of light intensity degree is higher than that of $\mathrm{P} 25$, thus $\mathrm{TiO}_{2} /$ $\mathrm{WO}_{3}$ might show stronger photocatalytic activity than P25.

Figure 8 displays the nitrogen adsorption-desorption isotherms and pore size distribution curve of $\mathrm{TiO}_{2} / \mathrm{WO}_{3}$ 600 and $\mathrm{P} 25$. The $\mathrm{TiO}_{2} / \mathrm{WO}_{3}-600$ in this work exhibits a type IV isotherm and a type $\mathrm{H}_{2}$ hysteresis loop [54]. The pore diameters of $\mathrm{TiO}_{2} / \mathrm{WO}_{3}-600$ and $\mathrm{P} 25$ are 8.5 and $9.9 \mathrm{~nm}$, 


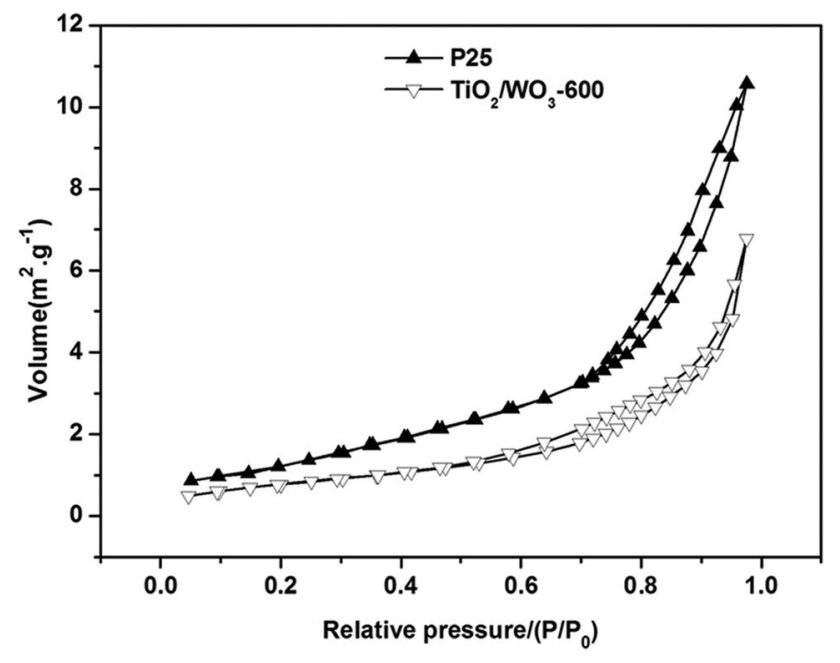

Fig. 8 BET curves of $\mathrm{TiO}_{2} / \mathrm{WO}_{3}-600$ nanoparticles (Ti:W=85:15, calcinated at $600^{\circ} \mathrm{C}$ ) and $\mathrm{P} 25$

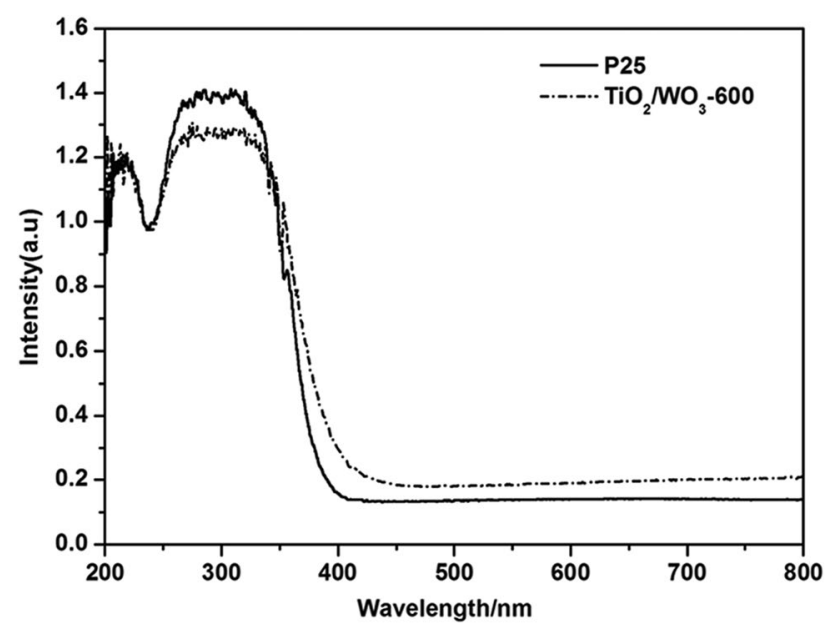

Fig. 9 UV-vis absorption spectra of $\mathrm{TiO}_{2} / \mathrm{WO}_{3}-600$ nanoparticles (Ti:W=85:15, calcinated at $600^{\circ} \mathrm{C}$ ) and $\mathrm{P} 25$

respectively, indicating the formation of mesoporous structure. The smaller pore size reflects the inhibition of grain growth and aggregation of residual carbon due to polymer carbonization [54].

Figure 9 shows the UV-vis absorption spectra of $\mathrm{TiO}_{2} /$ $\mathrm{WO}_{3}-600$ and $\mathrm{P} 25$. The enhanced absorption of $\mathrm{TiO}_{2} / \mathrm{WO}_{3}-$ 600 in the visible region can be attributed to the effect of $\mathrm{WO}_{3}$ doping. The fundamental absorption band edge of P25 stopped at around $400 \mathrm{~nm}$ and did not show any visible light absorption, however, $\mathrm{TiO}_{2} / \mathrm{WO}_{3}-600$ showed an absorption extending beyond $400 \mathrm{~nm}$. The difference in absorption characteristics of $\mathrm{P} 25$ and $\mathrm{TiO}_{2} / \mathrm{WO}_{3}-600$ proves that $\mathrm{WO}_{3}$ was successfully doped into $\mathrm{TiO}_{2}$ nanostructures. The visible light absorbance of $\mathrm{TiO}_{2} / \mathrm{WO}_{3}-600$
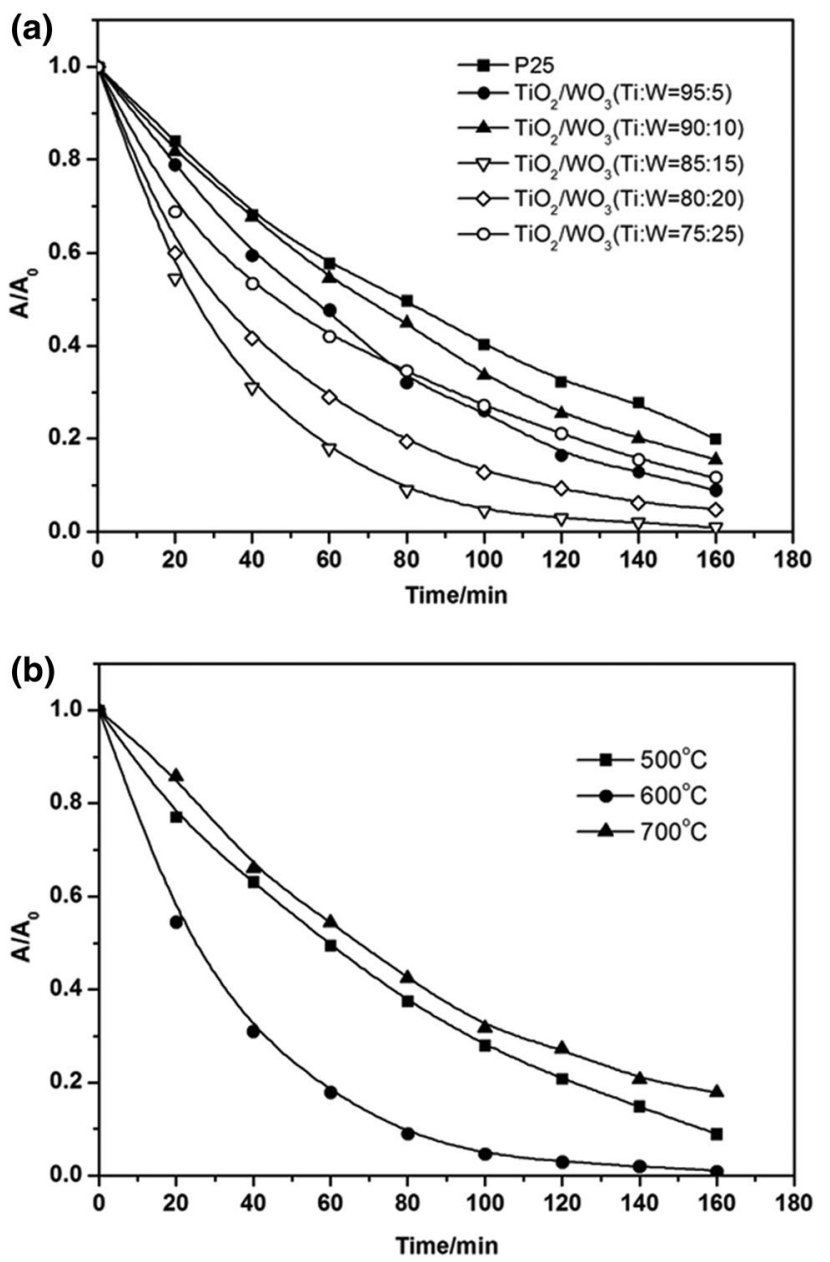

Fig. 10 Photodegradation curves of $\mathrm{MB}$ catalyzed by a $\mathrm{TiO}_{2} / \mathrm{WO}_{3}$ 600 nanoparticles ( $\mathrm{Ti}: \mathrm{W}=95: 5,90: 10,85: 15,80: 20$ and 75:25 respectively, calcinated at $600{ }^{\circ} \mathrm{C}$ ) and $\mathrm{P} 25 ; \mathbf{b ~ T i O} 2 / \mathrm{WO}_{3}$ nanoparticles (Ti:W $=85: 15$ ) calcianted at $500{ }^{\circ} \mathrm{C}, 600^{\circ} \mathrm{C}$ and $700^{\circ} \mathrm{C}$, respectively

is attributed to the existence of tungsten species such as $\mathrm{Ti}-\mathrm{O}-\mathrm{W}$ bonds.

In order to investigate the photo catalytic behaviour of the as-synthesized $\mathrm{TiO}_{2} / \mathrm{WO}_{3}$ nanopartilces, the photodegradation of $\mathrm{MB}$ as a model pollutant was carried out. Firstly, the MB solution $\left(10^{-3} \mathrm{~g} \mathrm{~L}^{-1}\right)$ was scanned at $200-800 \mathrm{~nm}$. It found that the maximum intensity of the characteristic peak of MB at $665 \mathrm{~nm}$ decreased with increasing the irradiation time. So the variation of absorbance at $665 \mathrm{~nm}$ was used to show the photodegradation curve of MB. The photodegradation of $\mathrm{MB}$ by $\mathrm{TiO}_{2} / \mathrm{WO}_{3}-600$ with different doping ratios and $\mathrm{P} 25$ are shown in Fig. 10a. When the molar ratio of $\mathrm{Ti} / \mathrm{W}$ is $85: 15$, the sample shows the best photocatalytic activity as MB can be completely photodegradation in shorter time. Besides all the doping act better photocatalytic activity compared with P25 under the same condition, this is due to the semiconductor of different width forbidden band compounded with each 
other, urging the separation of electronic- hole, reducing electronic restructuring, widen the range of spectral response, further improve the photocatalytic efficiency [55]. Figure $10 \mathrm{~b}$ shows the photodegradation curve of $\mathrm{MB}$ by $\mathrm{TiO}_{2} / \mathrm{WO}_{3}-600$ in doping ratio of $\mathrm{Ti}: \mathrm{W}=85: 15$ at different calcination temperature. It has been well understood that a higher activity can be achieved by improving many aspects of $\mathrm{TiO}_{2}$-based photocatalysts, including surface area, crystallinity, absorption ability, non-mental doping and water dispersity $[56,57]$. From a photocatalytic point of view, anatase is generally considered to be the more active phase due to its higher reduction potential and low re-combination rate of electron-hole pairs compared to rutile [58]. Therefore, the photocatalytic activity of $\mathrm{TiO}_{2} /$ $\mathrm{WO}_{3}-500$ is better than $\mathrm{TiO}_{2} / \mathrm{WO}_{3}-700$. While, due to the special electronic states, the two crystal structures allow for a semiconductor-semiconductor junction [59]. $\mathrm{TiO}_{2} /$ $\mathrm{WO}_{3}-600$ exhibits a higher photocatalytic activity than other photocatalysts. The $\mathrm{TiO}_{2} / \mathrm{WO}_{3}-600$ with the doping ratio of Ti:W $=85: 15$ can nearly completely degrade the $M B$ solution $\left(10^{-3} \mathrm{~g} \mathrm{~L}^{-1}\right)$ within $100 \mathrm{~min}$.

\section{Conclusions}

Visible-light active hybrid $\mathrm{TiO}_{2} / \mathrm{WO}_{3}$ spherical nanoparticles were successfully fabricated via a sol-gel process using an amphiphilic PCL-b-PAA diblock copolymer as template followed by calcination. In comparison with commercial catalyst $\mathrm{P} 25$, the hybrid $\mathrm{TiO}_{2} / \mathrm{WO}_{3}$ exhibited better catalytic behaviour in the photodegradation of MB. Doping ratio of Ti:W and calcination temperature, in our case, have a great significance on the catalytic activity of such hybrid $\mathrm{TiO}_{2} /$ $\mathrm{WO}_{3}$ nanoparticles. The best degradation activity was present by using the hybrid $\mathrm{TiO}_{2} / \mathrm{WO}_{3}$ nanoparticles with a doping ratio of Ti:W $=85: 15$ calcinated at $600^{\circ} \mathrm{C}$.

Acknowledgements The authors greatly appreciate the financial support from the National Natural Science Foundation of China (Nos. 50873093 and 21271156).

\section{Compliance with ethical standards}

Conflict of interest The authors declare that they have no conflict of interest.

\section{References}

1. McKeon-Fischer KD, Flagg DH, Freeman JW (2011) Poly(acrylic acid)/poly(vinyl alcohol) compositions coaxially electrospun with poly( $\varepsilon$-caprolactone) and multi-walled carbon nanotubes to create nanoactuating scaffolds. Polymer 52:4736-4743
2. Yao J, Wu H, Ruan Y, Guan J, Wang AN, Li HR (2011) “Reservoir" and "barrier" effects of ABC block copolymer micelle in hydroxyapatite mineralization control. Polymer 52:793-803

3. Zhu W, Li YL, Chen YM, Xi F (2012) Supramolecular hydrogels as a universal scaffold for stepwise delivering Dox and Dox/cisplatin loaded block copolymer micelles. Int J Pharm 437:11-19

4. Gou PF, Zhu WP, Xu N, Shen ZQ (2010) Synthesis and Self-assembly of well-defined cyclodextrin-centered amphiphilic A14B7 multimiktoarm star copolymers based on poly ( $\varepsilon$-caprolactone) and poly(acrylic acid). J Polym Sci Polym Chem 48:2961-2974

5. Hameed N, Guo QP (2008) Nanostructure and hydrogen bonding in interpolyelectrolyte complexes of poly( $\varepsilon$-caprolactone)block-poly(2-vinyl pyridine) and poly(acrylic acid). Polymer 49:5268-5275

6. Yuan C, Lu HC, Li QZ, Yang S, Zhao QL, Huang J, Wei LH, Ma Z (2012) Synthesis of well-defined amphiphilic polymethylene$b$-poly(caprolactone)-b-poly(acrylic acid) triblock copolymer via a combination of polyhomologation, ring-opening polymerization, and atom transfer radical polymerization. J Polym Sci Polym Chem 50:2398-2405

7. Niu DC, Liu XH, Li YS, Ma Z, Dong WJ, Chang S, Zhao WR, Gu JL, Zhang SJ, Shi JL (2011) Fabrication of uniform, biocompatible and multifunctional PCL-b-PAA copolymer-based hybrid micelles for magnetic resonance imaging. J Mater Chem 21:13825-13831

8. Arnal P, Corriu RJP, Leclercq D, Mutin PH, Vioux A (1997) A solution chemistry study of nonhydrolytic sol-gel routes to titania. Chem Mater 9:694-698

9. Sugimoto T, Zhou X, Muramatsu A (2002) Synthesis of uniform anatase $\mathrm{TiO}_{2}$ nanoparticles by gel-sol method. 1. Solution chemistry of $\mathrm{Ti}(\mathrm{OH})_{n}^{(4-n)+}$ complexes. J Colloid Interface Sci 252:339-346

10. Sugimoto T, Zhou X (2002) Synthesis of uniform anatase $\mathrm{TiO}_{2}$ nanoparticles by the gel-sol method 2. Adsorption of $\mathrm{OH}^{-}$ ions to $\mathrm{Ti}(\mathrm{OH})_{4} \mathrm{Gel}$ and $\mathrm{TiO}_{2}$ particles. J Colloid Interface Sci 252:347-353

11. Trung $\mathrm{T}$, Cho WJ, $\mathrm{Ha}$ CS (2003) Preparation of $\mathrm{TiO}_{2}$ nanoparticles in glycerol-containing solutions. Mater Lett 57:2746-2750

12. Lim KT, Hwang HS, Ryoo W, Johnston KP (2004) Synthesis of $\mathrm{TiO}_{2}$ nanoparticles utilizing hydrated reverse micelles in $\mathrm{CO}_{2}$. Langmuir 20:2466-2471

13. Li Y, Lee NH, Hwang DS, Song JS, Lee EG, Kim SJ (2004) Synthesis and characterization of nano titania powder with high photoactivity for gas-phase photo-oxidation of benzene from $\mathrm{TiOCl}_{2}$ aqueous solution at low temperatures. Langmuir 20:10838-10844

14. Kim KD, Kim SH, Kim HT (2005) Applying the Taguchi method to the optimization for the synthesis of $\mathrm{TiO}_{2}$ nanoparticles by hydrolysis of TEOT in micelles. Colloids Surf A 254:99-105

15. Lafond V, Mutin PH, Vioux A (2004) Control of the texture of titania-silica mixed oxides prepared by nonhydrolytic sol-gel. Chem Mater 16:5380-5386

16. Tang J, Redl F, Zhu Y, Siegrist T, Brus L, Steigerwald ML (2005) An organometallic synthesis of $\mathrm{TiO}_{2}$ nanoparticles. Nano Lett 5:543-548

17. Ruiz AM, Sakai G, Cornet A, Shimanoe K, Morante JR, Yamazoe N (2004) Microstructure control of thermally stable $\mathrm{TiO}_{2}$ obtained by hydrothermal process for gas sensors. Sens Actuators, B 103:312-317

18. Kolen'ko YV, Churagulov BR, Kunst M, Mazerolles L, ColbeauJustin C (2004) Photocatalytic properties of titania powders prepared by hydrothermal method. Appl Catal B 54:51-58

19. Nian JN, Teng H (2006) Hydrothermal synthesis of single-crystalline anatase $\mathrm{TiO}_{2}$ nanorods with nanotubes as the precursor. J Phys Chem B 110:4193-4198 
20. Das SK, Bhunia MK, Bhaumik A (2010) A self-assembled $\mathrm{TiO}_{2}$ nanoparticles: mesoporosity, optical and catalytic properties. Dalton Trans 39:4382-4390

21. Dutta S, Patra AK, De S, Bhaumick A, Saha B (2012) Self-assembled $\mathrm{TiO}_{2}$ nanospheres by using a biopolymer as a template and its optoelectronic application. ACS Appl Mater Interface 4:1560-1564

22. Kim CS, Moon BK, Park JH, Choi BC, Seo HJ (2003) Solvothermal synthesis of nanocrystalline $\mathrm{TiO}_{2}$ in toluene with surfactant. J Cryst Growth 257:309-315

23. Li XL, Peng Q, Yi JX, Wang X, Li YD (2006) Near monodisperse $\mathrm{TiO}_{2}$ nanoparticles and nanorods. Chem Eur J 12:2383-2391

24. Pradhan SK, Reucroft PJ, Yang F, Dozier A (2003) Growth of $\mathrm{TiO}_{2}$ nanorods by metalorganic chemical vapor deposition. J Cryst Growth 256:83-88

25. Wu JM, Zhang TW, Zeng YW, Hayakawa S, Tsuru K, Osaka A (2005) Large-scale preparation of ordered titania nanorods with enhanced photocatalytic activity. Langmuir 21:6995-7002

26. Wu JM, Shih HC, Wu WT (2005) Electron field emission from single crystalline $\mathrm{TiO}_{2}$ nanowires prepared by thermal evaporation. Chem Phys Lett 413:490-494

27. Mohammadi MR, Cordero-Cabrera MC, Fray DJ, Ghorbani M (2006) Preparation of high surface area titania $\left(\mathrm{TiO}_{2}\right)$ films and powders using particulate sol-gel route aided by polymeric fugitive agents. Sens Actuators, B 120:86-95

28. Sharma SK, Vishwas M, Narasimha Rao K, Mohan S, Reddy DS, Gowda KVA (2009) Structural and optical investigations of $\mathrm{TiO}_{2}$ films deposited on transparent substrates by sol-gel technique. J Alloys Compd 471:244-247

29. Li X, Fu XN, Yang H (2011) Preparation and photocatalytic activity of eccentric Au-titania core-shell nanoparticles by block copolymer templates. Phys Chem Chem Phys 13:2809-2814

30. Rawolle M, Ruderer MA, Prams SM, Zhong Q, Magerl D, Perlich J, Roth SV, Lellig P, Gutmann JS, Mueller-Buschbaum P (2011) Nanostructuring of titania thin films by a combination of microfluidics and block-copolymer-based sol-gel templating. Small 7:884-891

31. Chen ZX, Wang WX, Takao Y, Matsubara T, Ren LM (2012) Characterization and fatigue damage of $\mathrm{TiO}_{2}$ layer on spark-anodized titanium before and after hot water treatment. Appl Surf Sci 262:2-7

32. Wang XD, Xue XX, Li QY, Zhang M, Yang JJ (2012) Twice heat-treating to synthesize $\mathrm{TiO}_{2} /$ carbon composites with visible-lightphotocatalyticactivity. Mater Lett 88:79-81

33. Liu SH, Syu HR (2012) One-step fabrication of N-doped mesoporous $\mathrm{TiO}_{2}$ nanoparticles by self-assembly for photocatalytic water splitting under visible light. Appl Energy 100:148-154

34. Cheng XW, Yu XJ, Xing ZP, Yang LS (2012) Enhanced visible light photocatalytic activity of mesoporous anatase $\mathrm{TiO}_{2}$ codoped with nitrogen and chlorine. Int J Photoenergy 2012:593245

35. Pal U, Ghosh S, Chatterjee D (2012) Effect of sacrificial electron donors on hydrogen generation over visible light-irradiated nonmetal-doped $\mathrm{TiO}_{2}$ photocatalysts. Transit Metal Chem 37:93-96

36. Tan YN, Wong CL, Mohamed AR (2012) Hydrothermal treatment of fluorinated titanium dioxide: photocatalytic degradation of phenol. Asia-Pac J Chem Eng 7:877-885

37. Kim JH, Nishimura F, Yonezawa S, Takashima M (2012) Enhanced dispersion stability and photocatalytic activity of $\mathrm{TiO}_{2}$ particles fluorinated by fluorine gas. J Fluorine Chem 144:165-170

38. Chen YH, Xu TT, Li XY, Zhao QL, Huang J, Li YS, Wei LH, Ma Z (2013) The fabrication and characterization of $\mathrm{TiO}_{2}$ nanospheres with high visible light photocatalytic activity by direct carbonization of block copolymer templates. New J Chem 37:1115-1121

39. Park JY, Lee JH, Choi DY, Hwang CH, Lee JW (2012) Influence of Fe doping on phase transformation and crystallite growth of electrospun $\mathrm{TiO}_{2}$ nanofibers forphotocatalyticreaction. Mater Lett 88:156-159
40. Wang S, Lian JS, Zheng WT, Jiang Q (2012) Photocatalytic property of Fe doped anatase and rutile $\mathrm{TiO}_{2}$ nanocrystal particles prepared by sol-gel technique. Appl Surf Sci 263:260-265

41. Nogawa T, Isobe T, Matsushita S, Nakajima A (2013) Ultrasonication effects on the visible-light photocatalytic activity of Au-modified $\mathrm{TiO}_{2}$ powder. Mater Lett 90:79-82

42. Chauhan R, Kumar A, Chaudhary RP (2012) Structural and photocatalytic studies of $\mathrm{Mn}$ doped $\mathrm{TiO}_{2}$ nanoparticles. Spectrochim Acta A 98:256-264

43. Carcel RA, Andronic L, Duta A (2012) Photocatalytic activity and stability of $\mathrm{TiO}_{2}$ and $\mathrm{WO}_{3}$ thin films. Mater Charact 70:68-73

44. Yang JK, Zhang XT, Liu H, Wang CH, Liu SP, Sun PP, Wang LL, Liu YC (2013) Heterostructured $\mathrm{TiO}_{2} / \mathrm{WO}_{3}$ porous microspheres: preparation, characterization and photocatalytic properties. Catal Today 201:195-202

45. Ren CJ, Qiu W, Chen YQ (2013) Physicochemical properties and photocatalytic activity of the $\mathrm{TiO}_{2} / \mathrm{SiO}_{2}$ prepared by precipitation method. Sep Purif Technol 107:264-272

46. Fateh R, Dillert R, Bahnemann D (2013) Preparation and characterization of transparent hydrophilic photocatalytic $\mathrm{TiO}_{2} / \mathrm{SiO}_{2}$ thin films on polycarbonate. Langmuir 29:3730-3739

47. Zhang LF, Eisenberg A (1995) Multiple morphologies of "Crew-Cut" aggregates of polystyrene- $b$-poly(acrylic acid) block copolymers. Science 268:1728-1731

48. Zori MH (2011) Synthesis of $\mathrm{TiO}_{2}$ nanoparticles by microemulsion/ heat treated method and photodegradation of methylene blue. $J$ Inorg Organomet Polym Mater 21:81-90

49. Zurmühl C, Popescu R, Gerthsen D, Feldmann C (2011) Microemulsion-based synthesis of nanoscale $\mathrm{TiO}_{2}$ hollow spheres. Solid State Sci 13:1505-1509

50. Das D, Shivhare A, Saha S, Ganguli AK (2012) Room temperature synthesis of mesoporous $\mathrm{TiO}_{2}$ nanostructures with high photocatalytic efficiency. Mater Res Bull 47:3780-3785

51. Tripathi AK, Singh MK, Mathpal MC, Mishra SK, Agarwal A (2013) Study of structural transformation in $\mathrm{TiO}_{2}$ nanoparticles and its optical properties. J Alloys Compd 549:114-120

52. Oskam G, Nellore A, Lee Penn R, Searson PC (2003) The growth kinetics of $\mathrm{TiO}_{2}$ nanoparticles from titanium(IV) alkoxide at high water/titanium ratio. J Phys Chem B 107:1734-1738

53. Yamashita H, Ichihashi Y, Zhang SG, Matsumura Y, Souma Y, Tatsumi T, Anpo M (1997) Photocatalytic decomposition of NO at $275 \mathrm{~K}$ on titanium oxide catalysts anchored within zeolite cavities and framework. Appl Surf Sci 121:305-309

54. Kochuveedu ST, Jang YJ, Jang YH, Lee WJ, Cha M, Shin H, Yoon S, Lee S, Kim SO, Shin K, Steinhart M, Kim DH (2011) Visible-light active nanohybrid $\mathrm{TiO}_{2}$ /carbon photocatalysts with programmed morphology by direct carbonization of block copolymer templates. Green Chem 13:3397-3405

55. Ahmed MA, El-Katori EE, Gharni ZH (2013) Photocatalytic degradation of methylene blue dye using $\mathrm{Fe}_{2} \mathrm{O}_{3} / \mathrm{TiO}_{2}$ nanoparticles prepared by sol-gel method. J Alloys Compd 553:19-29

56. Zhang Q, Joo JB, Lu ZD, Dahl M, Oliveira D, Ye MM, Yin YD (2011) Self-assembly and photocatalysis of mesoporous $\mathrm{TiO}_{2}$ nanocrystal clusters. Nano Res 4:103-114

57. Ye MM, Zhang Q, Hu YX, Ge JP, Lu ZD, He L, Chen ZL, Yin YD (2010) Magnetically recoverable core-shell nanocomposites with enhanced photocatalytic activity. Chem Eur J 16:6243-6250

58. Fujishima A, Zhang XT, Tryk DA (2008) $\mathrm{TiO}_{2}$ photocatalysis and related surface phenomena. Surf Sci Rep 63:515-582

59. Woan K, Pyrgiotakis G, Sigmund W (2009) Photocatalytic carbonnanotube- $\mathrm{TiO}_{2}$ composites. Adv Mater 21:2233-2239

Publisher's Note Springer Nature remains neutral with regard to jurisdictional claims in published maps and institutional affiliations. 